\title{
Avaliação da Associação entre Doença Auto-Imune de Tireóide e Urticária Crônica Idiopática
}

\begin{abstract}
RESUMO
Vários estudos encontraram maior prevalência de Doença Auto-imune de Tireóide (DAT) em pacientes com Urticária Crônica (UC). Essa relação pode ocorrer devido à possível etiologia auto-imune em até um terço dos casos de Urticária Crônica Idiopática (UCI). No entanto, a freqüência de DAT variou de $1,14 \%$ a $28,6 \%$. O princípio deste estudo foi determinar se ocorre associação entre DAT e UCl em uma população atendida em um mesmo centro de saúde. Comparamos a freqüência de anticorpos antitireoidianos e disfunção tireoidiana entre 49 pacientes com $\mathrm{UCI}$ (grupo 1) e 112 controles (grupo 2). Com a finalidade de fortalecer o resultado encontrado, estudamos a prevalência de $\mathrm{UCl}$ em 60 pacientes com DAT (grupo 3) comparados com $29 \mathrm{com}$ doença não auto-imune de tireóide (DNAT) (grupo 4). Não encontramos diferença estatística quanto à presença de anticorpos anti-tireoidianos ou disfunção tireoidiana entre os grupos 1 e $2(12,24 \%$ x 9,82\% e 12,24\% x 7,14\%, respectivamente). 0 mesmo ocorreu quanto à presença de $\mathrm{UCl}$ entre os grupos 3 e 4 (3,33\% x $3,44 \%)$. Em nosso estudo não foi possível demonstrar uma relação entre DAT e UCl, o que significa que diferentes populações podem apresentar maior ou menor grau de associação entre essas doenças. (Arq Bras Endocrinol Metab 2007;51/7:1077-1083)
\end{abstract}

Descritores: Auto-imunidade; Glândula tireóide; Urticária; Autoanticorpos

\section{ABSTRACT}

\begin{abstract}
Assessment of Association Between Autoimmune Thyroid Disease and Chronic Urticaria.
\end{abstract}

Several studies found a higher prevalence of Autoimmune Thyroid Disease (ATD) in patients with Chronic Urticaria (CU). This relationship may be due to the possible autoimmune etiology in up to one third of the cases of Chronic Idiopathic Urticaria (CIU). However, the frequency of ATD ranged from $1.14 \%$ to $28.6 \%$. The study began by determining whether there is an association between ATD and CU, in a population seen at the same clinic. We compared the frequency of anti-thyroid antibodies and thyroid dysfunction in 49 patients with $\mathrm{CIU}$ (group 1) and 112 controls (group 2). In order to support the result found, we studied the prevalence of CIU in 60 patients with ATD (group 3) and compared with 29 patients who had non-immune thyroid disease (NITD) (group 4). We did not find a statistical difference for the presence of anti-thyroid antibodies or thyroid dysfunction between groups 1 and 2 (12.24\% $\times 9.82 \%$ and $12.24 \% \times 7.14 \%$, respectively). The same occurred for the presence of CIU among groups 3 and $4(3.33 \% \times 3.44 \%)$. In our study it was not possible to demonstrate a relationship between ATD and CIU, which means that different populations may present a higher or lower degree of association between these illnesses. (Arq Bras Endocrinol Metab 2007;51/7:1077-1083)

Keywords: Autoimmunity; Thyroid gland; Urticaria; Autoantibodies artigo original

\author{
TACIANA C.M. FEIBELMANN \\ FABRÍCIA TORRES GONÇALVES \\ Mariana Salomão DaUd \\ ANDRÉ DE SOUSA JORGE \\ SÔNIA A.O. MANTESE \\ Paulo tanNús Jorge
}

Serviço de Endocrinologia e Serviço de Dermatologia do Hospital de Clínicas da Faculdade de Medicina da Universidade Federal de Uberlândia (FM-UFU), Uberlândia, MG.

Recebido em 24/10/06

Revisado em 16/01/07

Aceito em 23/04/07 
A URTICÁRIA CRÔNICA (UC) É UMA doença caracterizada por lesões em pele eruptivas, pruriginosas, evanescentes, de variados tamanhos e formas, cujos episódios ocorrem por mais de seis semanas (1). Acomete $0,1 \%$ a $3 \%$ da população geral, tendo grande influência na qualidade de vida dos pacientes $(2,3)$. Além disto, em raros casos, há o risco de mortalidade devido à obstrução de vias aéreas superiores provocado por angioedema que acompanha a urticária em cerca de $50 \%$ das vezes $(4)$.

A causa da UC é encontrada em apenas 5\% a $30 \%$ dos casos (5). Quando um fator etiológico evidente não consegue ser identificado e são excluídos casos de urticária física, a urticária crônica é denominada idiopática. Neste grupo, o tratamento é apenas sintomático e seu resultado é frustrante em grande parte dos pacientes (6).

Assim, esforços para a compreensão dos mecanismos envolvidos na patogênese da UCI são importantes e estão sendo realizados para prover perspectivas de cura ou, pelo menos, tratamentos mais eficazes. Como resultado desses esforços, vários autores encontraram maior prevalência de DAT em pacientes com UCI (7-14). Esses achados levantam a possibilidade de uma relação entre essas doenças. Na UCI, verificou-se que até $50 \%$ dos pacientes podem ter uma origem auto-imune identificada pela presença em seu soro de auto-anticorpos anti-receptor de alta afinidade para IgE (anti-FceRI) ou, menos comumente, antiImunoglobulina E (anti-IgE) capazes de liberar histamina de basófilos e mastócitos (15). Esse achado, juntamente com a conhecida possibilidade de se encontrar associação de DAT com outras doenças autoimunes, sugere que DAT e UCI podem estar relacionadas, em alguns casos, por dividir um mesmo mecanismo no desencadeamento da doença nos órgãos-alvo em questão, a auto-imunidade.

No entanto, a freqüência de DAT em pacientes com UC variou, nos diversos estudos, de $1,14 \%$ a 28,6\% (7-14,16,17). Alguns autores, procurando reforçar a associação encontrada em muitos trabalhos, investigaram a freqüência de UCI em pacientes com DAT, obtendo resultados discrepantes $(13,18)$.

Assim, apesar de muitos trabalhos na literatura terem encontrado uma associação entre DAT e UC, ocorreu uma grande variabilidade entre as freqüências encontradas, seja por diferenças relacionadas à população em estudo e motivos específicos que serão discutidos oportunamente ou por dificuldades metodológicas, encontrados em alguns desses trabalhos. Não há estudos realizados no Brasil relacionados especialmente a este tema. O objetivo desta pesquisa foi determinar se ocorre associação entre UCI e DAT em uma população não anteriormente estudada, a fim de determinar se é justificável sempre investigar DAT em pacientes com UCI.

\section{PACIENTES E MÉTODOS}

Participaram do trabalho 250 pacientes atendidos consecutivamente nos ambulatórios de Dermatologia, Cirurgia de Cabeça e Pescoço e Endocrinologia e enfermaria de Endocrinologia do Hospital das Clínicas da Universidade Federal de Uberlândia no período de agosto de 2004 a maio de 2006. Trata-se de um estudo caso-controle onde os pacientes foram divididos em 4 grupos constituídos da seguinte forma:

Grupo $I(n=49)$ : pacientes com diagnóstico, realizado por um dermatologista, de UCI em atividade definida pela presença atual de lesões de pele típicas (urticas), com desa.parecimento em menos de 24 horas, recorrência mais de 4 vezes por semana durante 6 semanas ou mais e etiologia desconhecida, após investigação clínica e laboratorial;

Grupo $2(n=112)$ : pacientes atendidos no ambulatório de Dermatologia, sem urticária, com doenças de pele de etiologia conhecida, não alérgica ou auto-imune;

Grupo $3(n=60)$ : pacientes atendidos nos ambulatórios de Endocrinologia ou Cirurgia de Cabeça e Pescoço com diagnóstico de Tireoidite Crônica Auto-imune (TCA) ou Doença de Graves (DG). A primeira foi definida pela presença de qualquer anticorpo anti-tireoidiano associada ao hipotireoidismo ou a alterações ultrassonográficas compatíveis com TCA ou exame histológico confirmando a presença de infiltração linfocitária no tecido tireoidiano independente da presença de disfunção tireoidiana e anticorpos anti-tireoidianos. A segunda foi definida por hipertireoidismo associado à cintilografia com hipercaptação difusa da tireóide ou hipertireoidismo persistente por mais de 6 meses e bócio difuso ou exoftalmia;

Grupo $4(n=29)$ : pacientes atendidos no mesmo ambulatório do grupo 3 , que apresentavam DNAT incluindo bócio uni ou multinodular, bócio difuso colóide e câncer de tireóide, independente de tratamento prévio e sem nenhuma evidência de DAT.

Os grupos 1 e 2 foram comparados quanto à presença de anticorpos anti-tireoidianos, cuja positividade foi definida pelo método laboratorial utilizado e disfunção tireoidiana, definida como hipotireoidismo subclínico quando TSH apresentava-se elevado e T4 livre normal; hipotireoidismo clínico quando TSH elevado e T4 livre baixo; hipertireoidismo subclínico quando TSH baixo e T4 livre normal; ou hipertireoidismo clínico quando TSH baixo e T4 livre elevado. Em todos os pacientes foram dosados anticorpo antitireoglobulina (anti-Tg, VR até $45 \mathrm{UI} / \mathrm{mL}$ ), anticorpo antitireoperoxidase (anti-TPO, VR até $35 \mathrm{UI} / \mathrm{mL}$ ), hormônio tireoestimulante $(\mathrm{TSH}, \mathrm{VR}=0,4-4,0 \mathrm{mUI} / \mathrm{mL})$ e T4 livre 
$(\mathrm{T} 4 \mathrm{~L}, \mathrm{VR}=0,8-1,9 \mathrm{ng} / \mathrm{dL})$, por ensaio imunométrico, quimioluminescência (aparelho IMMULITE 200, kit DPC Medlab). Para o diagnóstico de UCI, os pacientes portadores de UC foram submetidos à investigação da etiologia da doença por história detalhada, exame físico e realização de exames laboratoriais incluindo hemograma, VHS, TGO, TGP, fator reumatóide (imunoturbidimetria), FAN (imunofluorescência), IgE total (quimioluminescência), exame simples de urina e exame parasitológico de fezes. Quando as enzimas hepáticas apresentaram-se alteradas, foi investigada hepatite viral pela realização de HBSAg e anti-HVC. Os exames laboratoriais acima foram realizados para afastar doenças hematológicas malignas (leucemias), doenças inflamatórias, hepatites virais, doenças reumatológicas, infecção urinária e parasitose intestinal, relatadas como possíveis causas de UC $(19,20)$.

Os grupos 3 e 4 foram constituídos por pacientes que já faziam controle na instituição e tinham diagnóstico da doença da tireóide bem definido pelos critérios descritos. Foram questionados e comparados entre si quanto à presença de UC, sendo considerados portadores da mesma quando a história clínica era compatível, e submetidos à mesma investigação para etiologia da UC realizada para os pacientes do grupo 1 .

Foram excluídos do estudo pacientes com urticária física ou para os quais foi encontrada uma clara etiologia para a urticária, menores de 16 anos, gestantes, portadores de hepatite viral e pacientes que estavam em uso de medicamentos capazes de interferir na função tireoidiana, como amiodarona, carbonato de lítio e interferon. A urticária física ocorre devido a um estímulo físico direto na pele, como frio, calor, luz solar, pressão ou vibração. Os pacientes foram considerados portadores deste tipo de urticária quando a história clínica apontava que a lesão surgia após contato com um desses agentes físicos (1).

O trabalho foi aprovado pelo Comitê de Ética e todos os sujeitos aceitaram participar do estudo após assinar consentimento livre e esclarecido.

A análise estatística foi realizada pelos testes do quiquadrado ou teste exato de Fisher two-tail para comparar variáveis categóricas; teste de Kolmogorov-Smirnof para testar normalidade dos dados, teste $t$ de Student para análise de dados paramétricos e de Mann-Whitney para os não paramétricos. Um valor de $\mathrm{p}<0,05$ foi considerado significativo.

\section{RESULTADOS}

\section{Características e comparação entre o grupo 1 (UCI) e o grupo 2 (controle)}

Entre 49 pacientes do grupo 1, portadores de UCI, 37 $(75,51 \%)$ eram do sexo feminino e $12(24,49 \%)$ do sexo masculino, com uma taxa mulheres/homens de $3 / 1$. Os participantes encontraram-se na faixa etária de 18 a 78 anos (média de $44,1 \pm 16,1$ anos). O tempo de evolução da UCI variou de 2 meses a 20 anos e 29 $(48,97 \%)$ pacientes tinham angioedema.
Em relação ao grupo 2 ou grupo controle, participaram 112 pacientes, dos quais $82(73,21 \%)$ eram do sexo feminino e $30(26,79 \%)$ do sexo masculino. A idade variou de 16 a 83 anos (média $=45,4 \pm$ 16,1 anos).

A prevalência de anticorpos anti-tireoidianos nos dois grupos está demonstrada na tabela 1. Em relação a esses resultados, não foi encontrada diferença estatisticamente significativa $(\mathrm{p}=0,64)$. Considerando um maior valor de ponto de corte para os anticorpos anti-tireoidianos (> $100 \mathrm{UI} / \mathrm{mL})$ a fim de diminuir a inclusão de resultados falso-positivos, estes estiveram presentes em 4 pacientes $(8,16 \%)$ do grupo 1 e 8 $(7,14 \%)$ do grupo 2 , também não ocorrendo diferença estatística $(\mathrm{p}=0,75)$.

Quanto à disfunção da tireóide, os pacientes apresentaram-se como demonstrado na tabela 2. Não houve diferença estatisticamente significativa $(\mathrm{p}=0,36)$ entre os dois grupos em relação à presença de qualquer tipo de alteração na função tireoidiana (tabela 2).

As características dos $9(18,36 \%)$ participantes do grupo 1 nos quais foi demonstrada alguma alteração em relação à presença de anticorpos anti-tireoidianos ou disfunção tireoidiana, estão demonstradas na tabela 3 . Este subgrupo foi comparado com os restantes 40 pacientes com UCI que não tiveram qualquer evidência de DAT, em relação a tempo de evolução de urticária, idade, valores de $\operatorname{IgE}$ total, presença de história familiar e pessoal de doença auto-imune e presença de angioedema. Não foi verificada diferença estatisticamente significante $(\mathrm{p}=\mathrm{NS})$ em relação a qualquer destes itens entre pacientes com UCI com ou sem doença de tireóide.

\section{Características e comparação entre o grupo 3 (portadores de DAT) e grupo 4 (portadores de DNAT)}

O grupo 3 foi constituído por 60 pacientes, 4 homens e 56 mulheres, idade média de $43,1 \pm 12$ anos. Vinte e sete (45\%) tinham diagnóstico de DG e 33 (55\%), de TCA. Dois $(3,33 \%)$ pacientes tinham história de UCI,

Tabela 1. Prevalência de anticorpos anti-tireoidianos em 49 pacientes com UCl (grupo 1) e 112 controles pareados de acordo com o sexo e idade (grupo 2).

\begin{tabular}{lcc}
\hline $\begin{array}{l}\text { Anticorpos } \\
\text { anti-tireoidianos }\end{array}$ & Grupo 1 (UCI) & $\begin{array}{c}\text { Grupo 2 } \\
\text { (controle) } \\
\text { n (\%) }\end{array}$ \\
Anti-TPO & n (\%) & $7(6,25 \%)$ \\
Anti-Tg & $6(12,24 \%)$ & $8(7,14 \%)$ \\
Total & $2(4,08 \%)$ & $11(9,82 \%)^{*}$ \\
\hline
\end{tabular}

* $\mathrm{p}=0,64$

Anti-TPO, anticorpo anti-tireoperoxidase; anti-Tg, anticorpo anti-tireoglobulina; UCl, urticária crônica idiopática. 
Tabela 2. Prevalência de disfunção tireoidiana em 49 pacientes com $\mathrm{UCl}$ (grupo 1) e 112 controles pareados de acordo com o sexo e idade (grupo 2).

\begin{tabular}{lcc}
\hline Disfunção & Grupo 1 (UCI) & Grupo 2 (controle) \\
& n (\%) & n (\%) \\
Hipotireoidismo sub-clínico & $2(4,08 \%)$ & $2(1,78 \%)$ \\
Hipotireoidismo clínico & $3(6,12 \%)$ & $3(2,67 \%)$ \\
Hipertireoidismo sub-clínico & $0(0 \%)$ & $3(2,67 \%)$ \\
Hipertireoidismo clínico & $1(2,04 \%)$ & $0(0 \%)$ \\
Total & $6(12,24 \%)^{*}$ & $8(7,14 \%)^{*}$ \\
\hline * p $=0,36$ & & \\
UCl, urticária crônica idiopática. & &
\end{tabular}

Tabela 3. Características e exames laboratoriais dos 9 pacientes com UCl e anticorpos anti-tireoidianos ou disfunção tireoidiana.

\begin{tabular}{|c|c|c|c|c|c|c|c|c|c|}
\hline Paciente & $\begin{array}{l}\text { Sexo/ } \\
\text { Idade } \\
\text { (anos) }\end{array}$ & $\begin{array}{l}\text { Tempo } \\
\text { de UC } \\
\text { (anos) }\end{array}$ & $\begin{array}{c}\text { TSH } \\
\mathrm{mUI} / \mathrm{mL}\end{array}$ & $\begin{array}{c}\text { T4L } \\
\text { ng/dL }\end{array}$ & $\begin{array}{c}\text { AntiTPO } \\
\text { Ul/mL }\end{array}$ & $\begin{array}{l}\text { AntiTg } \\
\text { Ul/mL }\end{array}$ & Angioedema & $\begin{array}{c}\text { HF de } \\
\text { doença } \\
\text { auto-imune }\end{array}$ & $\begin{array}{c}\text { HP de } \\
\text { doença } \\
\text { auto-imune }\end{array}$ \\
\hline $1^{*}$ & $F / 68$ & 2 & 2,0 & 1,3 & 20 & $<20$ & Ausente & - & - \\
\hline 2 & $\mathrm{~F} / 64$ & 3 & 4,9 & 1,1 & $<10$ & $<20$ & Ausente & - & - \\
\hline $3^{* *}$ & $\mathrm{~F} / 46$ & 20 & 20,8 & 0,8 & 39 & $>3000$ & Ausente & - & Vitiligo \\
\hline $4^{*}$ & $\mathrm{~F} / 41$ & 20 & 2,9 & 1,1 & 342 & $<20$ & Ausente & LES/irmã & - \\
\hline $5^{* * *}$ & $\mathrm{M} / 63$ & 4 & 0,006 & 3,7 & 20 & 22 & Ausente & - & - \\
\hline $6^{\dagger}$ & $F / 36$ & 0,6 & 0,5 & 1,2 & 70 & $<20$ & Ausente & - & - \\
\hline $7^{\dagger}$ & $\mathrm{F} / 50$ & 0,1 & 2,5 & 1,2 & 217 & $<20$ & Presente & - & Vitiligo \\
\hline 8 & $\mathrm{M} / 32$ & 5 & 2,3 & 1,4 & 41 & $<20$ & Presente & - & - \\
\hline $9^{+t}$ & $\mathrm{~F} / 66$ & 20 & 1,7 & 1,6 & $>1000$ & $>3000$ & Presente & $\begin{array}{l}\text { Doença de } \\
\text { Graves/filha }\end{array}$ & - \\
\hline
\end{tabular}

TSH, Hormônio tireoestimulante (VR =0,4-4,0 mUl/mL); T4L, T4 livre (VR =0,8-1,9 ng/dL); Anti-TPO, anti-tireoperoxidase (VR até 35 $\mathrm{IU} / \mathrm{mL}$ ); anti-Tg, anti-tireoglobulina (VR até $45 \mathrm{IU} / \mathrm{mL}$ ); a, anos; $\mathrm{m}$, meses; F, feminino; M, masculino.

* Hipotireoidismo compensado diagnosticado anteriormente, em uso de levotiroxina.

** Diagnóstico realizado durante o estudo.

** Diagnóstico realizado durante o estudo, ausência de bócio ou nódulo tireoidiano à palpação.

† Presença de anticorpos desconhecida anteriormente, sem disfunção tireoidiana.

†† Paciente com doença de Graves e hipotireoidismo após tireoidectomia, em uso de levotiroxina.

no momento ativa em ambos. Entre estes, um paciente tinha diagnóstico de DG e 1 de TCA, em tratamento com metimazol e levotiroxina, respectivamente. A UC precedeu o diagnóstico da DAT nos dois pacientes.

O grupo 4 foi constituído por 29 sujeitos, 3 homens e 26 mulheres, idade média de 51,6 \pm 13,6 anos. Dez apresentavam neoplasia tireoidiana, 7 bócio colóide, 8 nódulo tireoidiano benigno e 3 bócio multinodular. UCI foi encontrada em l paciente com bócio multinodular e hipertireoidismo compensado, em tratamento com tapazol. A doença de pele estava presente há 8 anos e doença tireoidiana havia sido diagnosticada há 3 anos.

Não houve diferença estatística quanto à freqüência de urticária crônica entre os dois grupos ( $\mathrm{p}$ $=1,00)($ tabela 4$)$.

\section{DISCUSSÃo}

A associação entre UC e DAT foi descrita por vários autores, sendo considerada bem estabelecida (714,21). Em nosso trabalho, concordando com poucos relatos, esta associação não ocorreu $(16,17)$.
Em estudos onde foi encontrada maior prevalência de DAT em pacientes com UC, observou-se melhora das lesões de pele em alguns pacientes após tratamento com levotiroxina $(8,22,23)$. Os autores sugerem que existe uma relação de causa e efeito, ou seja, DAT levaria ao desencadeamento da UCI. Outros, no entanto, acreditam que, na verdade, uma parcela dos pacientes com UCI tem uma etiologia auto-imune e sua relação com DAT ocorre pela já conhecida maior possibilidade de se encontrar diferentes doenças auto-imunes entre pacientes susceptíveis, como é demonstrado, por exemplo, pela maior prevalência de vitiligo, alopecia areata, doença de Adisson e diabetes mellitus tipo $1 \mathrm{em}$ pacientes com DAT $(10,24,25)$.

Os casos de urticária crônica auto-imune podem ser rastreados pelo teste do soro autólogo (TSA), onde ocorre lesão característica no local onde é injetado soro do próprio paciente via intradérmica (26). Assim, considerando que pelo menos uma parcela dos pacientes com UCI tem, na verdade, uma doença autoimune, seria plausível acreditar que uma associação com DAT realmente exista, visto tratar-se de duas doenças com mecanismos patogênicos semelhantes. 
Tabela 4. Freqüência de Urticária Crônica em pacientes com DAT (grupo 3) e DNAT (grupo 4).

\begin{tabular}{lcc}
\hline Urticária Crônica & $\begin{array}{c}\text { DAT } \\
\text { (grupo 3) }\end{array}$ & $\begin{array}{c}\text { DNAT } \\
\text { (grupo 4) }\end{array}$ \\
Presente & $2(03,33 \%)^{*}$ & $1(03,44 \%)^{*}$ \\
Ausente & $58(96,67 \%)$ & $28(96,56 \%)$ \\
Total & $60(100 \%)$ & $29(100 \%)$ \\
\hline
\end{tabular}

${ }^{*} \mathrm{p}=1,00$

DAT, doença auto-imune de tireóide; DNAT, doença não auto-imune de tireóide.

No entanto, entre os trabalhos que encontraram uma associação entre DAT e UC, a maioria apresentou dificuldades metodológicas (7-11). A prevalência de anticorpos anti-tireoidianos em pacientes com UC variou de $11,7 \%$ a $28,6 \%$. Em alguns desses estudos $(7,8,10)$, a freqüência encontrada pelos autores nos pacientes com UC foi semelhante à nossa $(11,7 \% ; 12,1 \%$; $14 \% \times 12 \%$, respectivamente), mas, ao contrário deles, não encontramos diferença com o grupo controle. Os grupos controle de alguns trabalhos não foram pareados de acordo com os pacientes com UC (7), enquanto outros usaram como comparação dados de estudos epidemiológicos $(8,9,11)$. Isso pode ter levado a conclusões equívocas já que a prevalência de DAT é influenciada por diferenças regionais, principalmente em relação ao consumo de iodo (27). Assim, o ideal é que se utilize um grupo controle constituído por sujeitos da mesma região. Além disso, DAT vem aumentando devido aos programas de iodação do sal (28), logo, a comparação de dados recentes com estudos epidemiológicos mais antigos poderia mostrar uma diferença de prevalência que não existe. Outro aspecto é que DAT é mais comum no sexo feminino e na faixa etária acima de 40 anos, como ocorre também na UC $(4,29,30)$. Assim, comparar uma série de pacientes portadores de UC com dados de estudos epidemiológicos que contêm semelhante número de homens e mulheres e inclui várias faixas etárias pode levar a erros na interpretação dos dados. Além disso, outros autores utilizaram para a análise estatística diferentes critérios de presença de anticorpos anti-tireoidianos para os pacientes com UC e controles (qualquer anticorpo positivo para o primeiro grupo e apenas ambos positivos para o segundo) (10). Assim, se considerássemos o mesmo critério para os dois grupos, não haveria diferença estatística e, portanto, não se poderia concluir a favor de uma associação entre as duas doenças, como foi feita.

Por outro lado, em outros estudos, foi encontrada uma associação entre DAT e UC utilizando uma metodologia mais adequada (12-14). Kullavanijaya e cols. (12) demonstraram uma prevalência de anticorpos anti-tireoidianos em pacientes com UCI de
$21 \%$ contra $9 \%$ no grupo controle. A freqüência descrita por Verneuil e cols. (13) foi de $26 \%$ e $3,3 \%$, respectivamente, e por Toubi e cols. (14), de $12 \%$ e $0 \%$, respectivamente. No primeiro encontramos semelhança com os nossos dados em relação ao grupo controle $(9,82 \%$ em nosso trabalho e $9 \%$ no de Kullavanijaya e cols.). No entanto, no grupo de doentes com UC a prevalência foi bem maior que a descrita em nossa série de pacientes $(21 \%$ x 12\%, respectivamente) (12). Por outro lado, Toubi e cols. (14) relatou uma freqüência semelhante à encontrada em nosso estudo em relação aos portadores de UC, mas em seu grupo controle não foi encontrada DAT.

Outros autores descreveram uma freqüência muito pequena de DAT em pacientes com UC $(1,14 \%$ e $2,0 \%)(16,17)$. Esses resultados podem ter sido subestimados, pois não se tem informação se ocorreram casos de positividade de anticorpos sem comprometimento da produção hormonal, visto que todos os pacientes relatados com DAT tinham ambos, anticorpos positivos e disfunção tireoidiana. Além disso, esses estudos não foram designados especificamente para este fim. Apesar das considerações acima, seus resultados chamam a atenção para o fato de que é possível que, nem sempre, a freqüência de DAT em pacientes com UC seja importante, visto que a prevalência encontrada é semelhante à da população geral.

Esta discrepância nos diversos trabalhos se mantém quando analisamos a freqüência de UCI em pacientes com doença tireoidiana. Espera-se, considerando a possibilidade de associação entre as duas doenças, que também se encontre mais casos de UCI entre pacientes com DAT do que naqueles com DNAT ou na população geral. No entanto, há apenas dois estudos anteriores ao nosso que avaliaram esta prevalência, tendo encontrado resultados discrepantes $(13,18)$. Em nosso trabalho, não encontramos maior freqüência de UCI em pacientes com DAT quando comparados a pacientes com DNAT, concordando com o achado de ausência de relação entre essas doenças quando avaliamos presença de DAT em pacientes com UCI. Não tivemos um grupo controle com uma amostra de sujeitos não acometidos por qualquer doença tireoidiana, porém Lanigan e cols. (18) relataram maior prevalência de UCI em pacientes com DAT do que em dois grupos controles: um de pacientes com doença tireoidiana sem auto-anticorpos e outro de pacientes sem doenças de tireóide, sugerindo que, quando ocorre, esta associação está relacionada à presença de auto-imunidade.

Assim, há uma grande diferença entre os dados encontrados por vários autores. Muitos fatores podem explicar essa discrepância. A metodologia científica 
variou nos diversos trabalhos incluindo diferenças nos ensaios usados para dosagem de anticorpos anti-tireoidianos e nos valores de corte considerados, mesmo quando um único ensaio foi utilizado; definição de diferentes critérios diagnósticos para DAT e UC e, mais importante, composição dos grupos controle. Outro fato importante é que, como no nosso caso, não se avaliou em todos os trabalhos qual a percentagem de Urticária Crônica Auto-imune (UCA) entre todos os casos de UC. O'Donell e cols. (24), em seu estudo, demonstraram que a associação entre UC e DAT ocorre apenas em um seleto grupo de pacientes com um TSA positivo que os classifica como portadores de UCA. Os mesmos encontraram anticorpos anti-tireoidianos positivos em $20 \%$ de 90 pacientes com UC e TSA positivo e em $4,34 \%$ de 92 pacientes com o teste negativo. Considerando o grupo como um todo $(\mathrm{n}=$ 182), descreveram uma taxa de $12,08 \%$, próximo da prevalência encontrada em nosso trabalho. Como toda doença auto-imune, provavelmente a UCA depende de fatores genéticos (genes de susceptibilidade, haplótipos de HLA) associados a fatores que gerariam a ativação do processo de auto-imunidade. Estes podem ser ambientais, incluindo exposição a certos alimentos, agentes infecciosos, tipo de clima, estilo de vida e inúmeros outros, sendo aqui apenas especulativos. Diferentes populações podem apresentar características genéticas e ambientais que predispõem a um maior número de UCA entre todos os casos de UC. Assim, nestas, provavelmente encontraremos também maior prevalência de DAT, mesmo considerando a amostra como um todo. Na nossa amostra e na de outros estudos onde não se pôde demonstrar associação entre as duas doenças, pode ter ocorrido que a maioria, ou pelo menos grande parte, dos pacientes não tenha qualquer indício de auto-imunidade em relação à sua doença de pele, como encontrado por O'Donnel e cols. (24). Desta forma, a probabilidade de se encontrar maior prevalência de DAT quando se estuda um pool de pacientes com UCI, dependeria do número de casos com UCA existentes. Se estes são poucos, a associação entre as duas doenças pode não ser verificada.

Outro aspecto interessante é que, provavelmente, a presença isolada de auto-imunidade não é o único fator que prediz uma associação entre as duas doenças. Alguns autores, por exemplo, encontraram alta taxa de UCA em pacientes com UC (43\%), porém baixa prevalência de DAT (2\%) (16). Destaca-se aqui também o trabalho de Bakos e Hillander (31), que analisando pacientes com UCA com e sem DAT, encontraram uma freqüência de infecção por H. pylory de $90,9 \%$ contra $46,7 \%$, respectivamente. A cepa com o antígeno de $120 \mathrm{KDa}$ CagA também foi mais prevalente no grupo com DAT. Acredita-se que esta cepa de H. pylory, por produzir uma peroxidase muito semelhante à tireoperoxidase, pode levar à autoimunidade tireoidiana por um mecanismo de mimetismo molecular. Assim, alguns pacientes com UCA teriam maior prevalência de anticorpos anti-tireoidianos se também fossem expostos a determinadas cepas de H. pylory. Apesar de ser um único trabalho e haver a necessidade de outros estudos para confirmar esses achados, os resultados encontrados apontam para a possibilidade de que vários fatores, a maioria provavelmente desconhecidos, possam contribuir para diferentes associações ou prevalências de DAT entre pacientes com UC.

Outra questão a ser levantada é a alta freqüência de anticorpos anti-tireoidianos no grupo controle encontrada em nosso trabalho, diferente da maioria dos relatos de outros autores $(7,10,13,14)$. Ressaltando as críticas já realizadas quanto à composição dos grupos controle em alguns destes estudos, a alta prevalência de DAT no nosso grupo pode ter ocorrido devido à maior proporção de mulheres em relação aos homens. No entanto, também pode ter sido influenciada pelo aumento progressivo da incidência de DAT devido ao maior consumo de iodo pela população, como já relatado acima (28). Isto também seria um dos fatores que poderiam explicar os resultados negativos encontrados em nosso estudo. Ora, se duas doenças podem ocorrer juntas como UC e DAT, ligadas por um mecanismo fisiopatológico comum, no caso a auto-imunidade, um fator ambiental diferente que favoreça a maior incidência de apenas uma poderia diminuir o grau de associação entre as duas doenças. Assim, se DAT vem aumentando devido à maior ingestão de iodo e este fator não tem relação com o desencadeamento da urticária, mais pacientes poderão apresentar DAT sem urticária.

Assim, alguns fatores podem ser mais importantes na indução de DAT, outros na indução de UCA e ainda outros podem contribuir para esta associação quando uma das doenças, UC ou DAT, já estiver presente, contribuindo para a grande discrepância entre os dados encontrados na literatura.

\section{CONCLUSÃO}

Não foi possível demonstrar, em nosso trabalho, a associação entre DAT e UCI sugerida por vários outros autores. Isso indica que, pelo menos em algumas populações, esta pode não existir, não se jus- 
tificando a investigação rotineira de DAT em pacientes com UCI e vice-versa. Outros trabalhos, com amostras maiores, deverão ser realizados para melhor compreensão destes achados.

\section{REFERÊNCIAS}

1. Zuberbier T, Bindslev-Jensen C, Canonica W, Grattan CEH, Greaves MW, Henz BM, et al. EAACl/GA2LEN/EDF guideline: definition, classification and diagnosis of urticaria. Allergy 2006;61(3):316-20.

2. Sabroe RA, Greaves MD. The pathogenesis of chronic idiopathic urticaria. Arch Dermatol 1997;133:1003-8.

3. O'Donnell BF, Lawlor F, Simpson J, Morgan M, Greaves MW. The impact of chronic urticaria on the quality of life. $\mathbf{B r} \mathbf{J}$ Dermatol 1997; 136(2):197-201

4. Dibbern DA, Dreskin SC. Urticaria and angioedema: an overview. Immunol Allergy Clin N Am 2004:24(2):141-62.

5. Staumont-Sallé D, Piette F, Delaporte E. Etiological diagnosis and treatment of chronic urticaria. Rev Med Interne 2003;24:34-44.

6. Rumbyrt JS, Schocket AL. Chronic urticaria and thyroid disease. Immunol Allergy Clin N Am 2004;24(2):215-23.

7. Leznoff A, Josse RG, Denburg J, Dolovich J. Association of chronic urticaria and angioedema with thyroid autoimmunity. Arch Dermatol 1983;119:636-40.

8. Leznoff A, Sussman GL. Syndrome of idiopathic chronic urticaria and angioedema with thyroid autoimmunity: A study of 90 patients. J Allergy Clin Immunol 1989;84(1):66-71.

9. Collet E, Petit JM, Lacroix M, Bensa AF, Morvan C, Lambert D. Urticaire chronique et pathologie thyroidienne autoimune. Ann Dermatol Venereol 1995;122:413-6.

10. Turktas I, Gokcora N, Demirsoy S, Cakir N, Onal E. The association of chronic urticaria and angioedema with autoimmune thyroiditis. Int J Dermatol 1997;36(3):187-90.

11. Zauli D, Deleonard G, Foderaro S, Grassi A, Bortolotti R, Ballardini G, et al. Thyroid autoimmunity in chronic urticaria. Allergy Asthma Proc 2001;22(2):93-5.

12. Kullavanijaya P, Puavilai G, Puavilai $S$, Chanprasertyothin $S$. Prevalence of thyroid antibodies in Thai patients with chronic idiopathic urticaria. J Med Assoc Thai 2002;85(8):901-6.

13. Verneuil CL, Leconte C, Ballet JJ, Coffin C, Laroche D, Izard $\mathrm{JP}$, et al. Association between chronic urticaria and thyroid autoimmunity: A prospective study involving 99 patients. Dermatology 2004;208(2):98-103.

14. Toubi E, Kessel A, Avshovich N, Bamberger E, Sabo E, Nusem $D$, et al. Clinical and laboratory parameters in predicting chronic urticaria duration: a prospective study of 139 patients. Allergy 2004;59:869-73.

15. Sabroe RA, Greaves MW. Chronic idiopathic urticaria with functional autoantibodies: 12 years on. Br J Dermatol 2006; $154: 813-9$

16. Nettis E, Pannofino A, D'Aprile C, Ferrannini A, Tursi A. Clinical and aetiological aspects in urticaria and angio-oedema. Br J Dermatol 2003;148(3):501-6.
17. Pigatto PD, Valsecchi RH. Chronic urticaria: a mystery. Allergy 2000;55(3):306-8

18. Lanigan SW, Short P, Moult P. The association of chronic urticaria and thyroid autoimmunity. Clin Exp Dermatol 1987;12(5):334-8.

19. Zuberbier T, Bindslev-Jensen C, Canonica W, Grattan CE, Greaves MW, Henz BM, et al. EAACI/GA2LEN/EDF guideline: management of urticaria. Allergy 2006;61(3):321-31.

20. Criado RF, Criado PR, Sittart JA, Pires MC, de Mello JF, Aun WT. Urticária e doenças sistêmicas. Rev Assoc Med Bras 1999;45(4):349-56.

21. Doutre MS. Chronic urticaria and thyroid auto-immunity. Clin Rev Allergy Immunology 2006;30:31-7.

22. Rumbyrt JS, Katz JL, Schocket AL. Resolution of chronic urticaria in patients with thyroid autoimmunity. J Allergy Clin Immunol 1995;96(6):901-5.

23. Aversano M, Caiazzo P, Lorio G, Ponticiello L, Laganá, B, Leccese F. Improvement of chronic urticaria with L-thyroxine: a new TSH role in immune response? Allergy 2005;60:489-93.

24. O'Donnell BF, Francis DM, Swana GT, Seed PT, Kobza Black A, Greaves MW. Thyroid autoimmunity in chronic urticaria. Br J Dermatol 2005;153:331-5.

25. Dreskin SC, Andrews KY. The thyroid and urticaria. Curr Opin Allergy Clin Immunol 2005;5:408-12.

26. Sabroe RA, Grattam CEH, Francis DM, Barr RM, Kobsa Black A, Greaves MW. The autologous serum skin test: a screening test for autoantibodies in chronic idiopatic urticaria. $\mathbf{B r} \mathbf{J}$ Dermatol 1999;140(3):446-52.

27. Pedersen IB, Knudsen N, Jøgensen $T$, Perrild $H$, Ovesen $L$, Laurberg P. Thyroid peroxidase and thyroglobulin autoantibodies in a large survey of populations with mild and moderate iodine deficiency. Clin Endocrinol (Oxf) 2003;58(1):3642.

28. Markou KB, Georgopoulos NA, Makri M, Vlasopoulou B, Anastasiou $E$, Vagenakis GA, et al. Improvement of iodine deficiency after iodine supplementation in schoolchildren of Azerbaijan was accompanied by hypo and hyperthyrotropinemia and increased title of thyroid autoantibodies. $\mathbf{J}$ Endocrinol Invest 2003;26(suppl.2):43-8.

29. Prummel MF, Strieder T, Wiersinga WM. The environment and autoimmune thyroid diseases. Eur $\mathbf{J}$ Endocrinol 2004; $150: 605-18$.

30. Hollowell JG, Staehling NW, Flanders WD, Hannon WH, Gunter EW, Spencer CA, et al. Serum TSH, T4, and thyroid antibodies in the United States population (1988 to 1994): National Health and Nutrition Examination Survey (NHANES III). J Clin Endocrinol Metab 2002;87(2):489-99.

31. Bakos N, Hillander M. Comparison of chronic autoimmune urticaria with chronic idiopathic urticaria. Int J Dermatol 2003;42:613-5.

Endereço para correspondência:

Paulo Tannús Jorge

Rua Cruzeiro dos Peixotos 499, sala 303

38400-608 Uberlândia, MG 